\title{
Estenosis traqueal y cicatrización queloide
}

\section{Tracheal stenosis and keloid scar}

Jorge A. Castañón-González ${ }^{1,2 \star}$, José C. Gasca-Aldama1, Karen Castillo-Medrano', Alexei H. Morales-Morales y Miguel A. García-Cruz ${ }^{1}$

${ }^{1}$ Unidad de Cuidados Intensivos y Medicina Crítica; ${ }^{2}$ Servicio de Cirugía General. Hospital Juárez de México, Ciudad de México, México

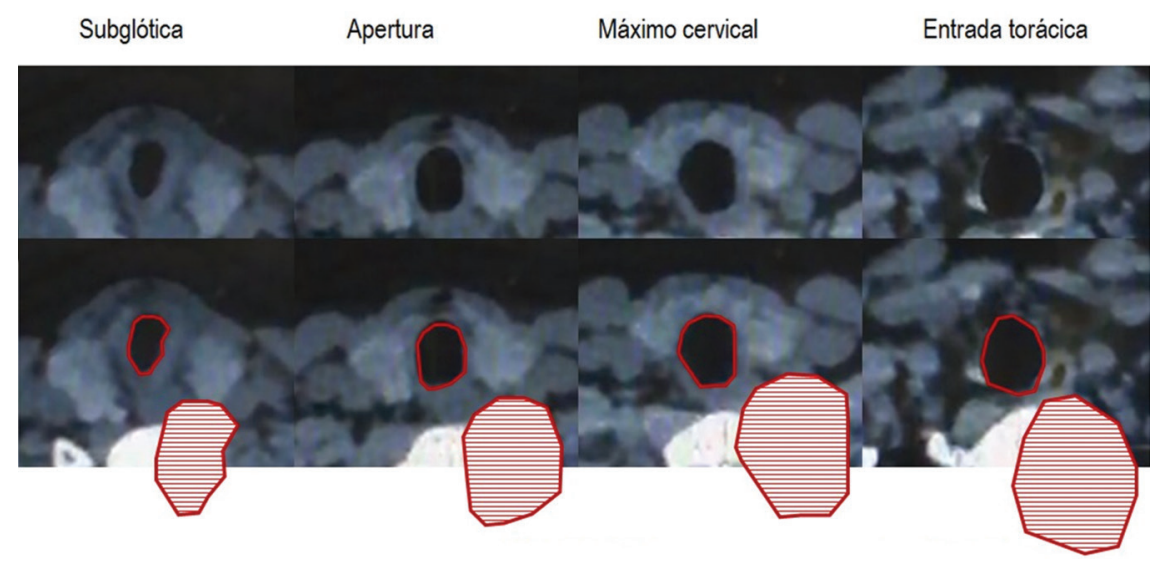

Figura 1. Comparación de los diámetros traqueales. Estenosis traqueal, subglótica, de apertura súbita del $40 \%$ del diámetro efectivo torácico y del $50 \%$ del diámetro cervical.

\section{Sr. Editor:}

La frecuencia de estenosis traqueal posterior a intubación orotraqueal varía entre el 10 y el $22 \%$, dependiendo de la serie consultada; sin embargo, la estenosis grave se presenta solo en el $2 \%$ de los casos $^{1}$. La cicatrización queloide o hipertrófica, que tiene una incidencia entre el 4 y el $16 \%$ en la población mexicana, es un factor de riesgo reconocido para estenosis traqueal que con frecuencia pasa desapercibido $^{2}$. Con la idea de resaltar esta complicación grave, presentamos un caso prototipo.
Una mujer de 27 años, con antecedente de intubación previa por 9 días secundaria a un intento suicida efectuado 21 meses antes, fue admitida a hospitalización por estridor y disnea con un embarazo de 34 semanas complicado con preeclampsia sintomática. Durante su evaluación se corroboró por tomografía computarizada de cuello una estenosis subglótica con un calibre de la vía aérea de $5 \mathrm{~mm}$ (Fig. 1); la evaluación radiológica incluyó al servicio de cirugía torácica. En la exploración física destacaron múltiples cicatrices queloides en los antebrazos por lesiones

\section{Correspondencia:}

*Jorge A. Castañón-González

Avda. Instituto Politécnico Nacional, 5160

Col. Magdalena de las Salinas, Del. Gustavo A. Madero

C.P. 07760 , Ciudad de México, México

Fecha de recepción: 10-01-2019

Fecha de aceptación: 03-06-2020

E-mail: jorge.castanong@gmail.com
Cir Cir. 2020;88(6):820-821

Contents available at PubMed

www.cirugiaycirujanos.com (http://creativecommons.org/licenses/by-nc-nd/4.0/). 
autoinfligidas. Debido a su condición obstétrica, se efectuó cesárea de urgencia previo aseguramiento de la vía aérea por medio de traqueostomía. La evolución de la paciente fue sin eventualidades y egresó para continuar seguimiento como externa y programar traqueoplastia en forma electiva. El reporte de la biopsia descartó otras patologías.

Debido a su frecuencia, la identificación de la cicatrización queloide se deberá tener en cuenta por todos los médicos involucrados en el manejo de la vía aérea, con la finalidad de tratar de evitar la intubación orotraqueal por medio de cánulas laríngeas ${ }^{3}$. Cuando esto no sea factible, el objetivo será retirar la cánula orotraqueal lo más temprano posible ${ }^{4,5}$.

\section{Conflicto de intereses}

Los autores declaran que no existe conflict de intereses.

\section{Bibliografía}

1. Frioui S, Khachnaoui F. Severe tracheal stenosis after prolonged intubation. Pan Afr Med J. 2017;28:247.

2. Alcalá PD, Llergo VR. Cicatrices hipertróficas y queloides. Rev Cent Dermatol Pascua. 2006;15(1):31-4.

3. Choi SS, Zalzal GH. Pitfalls in laryngotracheal reconstruction. Arch Otolaryngol Head Neck Surg. 1999;125:650-3.

4. Raman R, Arumainathan U, Subramaniam S, Chan L, Jalaludin MA. Hypertrophic scars, keloids, and laryngotracheal stenosis. Plastic Reconstr Surg. 1999;103:1539.

5. Jefferson ND, Cohen AP, Rutter MJ, Nemeh AJ. Keloids and hypertrophic scars. J Dermatol Surg Oncol. 1993;19:738-46. 